\title{
Treating to goal: challenges of current management
}

\author{
A H Barnett \\ University of Birmingham and Birmingham Heartlands Hospital, Department of Medicine Undergraduate Centre, Bordesley Green East, \\ Birmingham, B9 5SS, UK
}

(Correspondence should be addressed to A H Barnett; Email: anthony.barnett@heartsol.wmids.nhs.uk)

\begin{abstract}
Extensive evidence supports the benefits of treating to glycated haemoglobin $\left(\mathrm{HbA}_{1 \mathrm{c}}\right)$ goal, both in terms of health and economic outcomes. As shown by the UK Prospective Diabetes Study (UKPDS) and the Diabetes Control and Complications Trial (DCCT), the risk of patients with type 2 diabetes developing vascular complications is strongly correlated with $\mathrm{HbA}_{1 \mathrm{c}}$ levels and the duration of poor glycaemic control. Moreover, good glycaemic control significantly reduces the risk of complications. In controlled clinical trials, a number of pharmacological agents have been shown to significantly reduce $\mathrm{HbA}_{1 \mathrm{c}}$ levels in patients with type 2 diabetes. However, the reality is that most patients with type 2 diabetes have $\mathrm{HbA}_{1 \mathrm{c}}$ levels above the recommended target levels. Although there are regional differences in the average $\mathrm{HbA}_{1 \mathrm{c}}$ level, poor glycaemic control is a universal problem that will continue to grow in line with the rapidly increasing prevalence of type 2 diabetes.

Barriers to good blood glucose control are present in almost every aspect of diabetes care. Furthermore, in patients with type 2 diabetes, therapy-, patient- and/or healthcare system-related barriers are compounded by an ongoing decline in beta-cell function that is characteristic of the progressive nature of the disease. Therapy-related barriers include reduced long-term efficacy with oral agents, fear of hypoglycaemia and a variety of issues related to flexibility and convenience that encourage poor compliance with therapy. From the patient perspective, issues relating to lifestyle, education, psychology and the environment can prevent optimum diabetes self-management. Poor access to and/or use of specialist healthcare resources also has a negative effect on treatment outcomes. These barriers to glycaemic control need to be overcome so that the established benefits of reducing glucose to normal or near-normal levels can be experienced by more people with type 2 diabetes.
\end{abstract}

European Journal of Endocrinology 151 T3-T7

\section{Diabetes treatment goals}

Before exploring some of the many challenges of treating to goal, it is necessary to answer the question 'What is the treatment goal?'. Diabetes is a complex disease that requires the management of glucose, blood pressure, lipid levels and thrombotic status. With respect to blood glucose goals - the focus of this article - glycated haemoglobin $\left(\mathrm{HbA}_{1 \mathrm{c}}\right)$, fasting plasma glucose and postprandial plasma glucose levels can be measured to gauge the degree of metabolic control. Although it is desirable to normalise each of these glucose parameters, $\mathrm{HbA}_{1 \mathrm{c}}$ is generally used as the standard measurement for intervention and treatment.

Diabetes treatment goals can and indeed should be tailored for the individual patient, taking into consideration the stage of the disease, their commitment and ability to carry out self-care, the presence of comorbidities and the risk of hypoglycaemia. However, general diabetes treatment guidelines have been developed using data from several landmark diabetes intervention studies. The Diabetes Control and Complications Trial (DCCT) (1) and the Stockholm Diabetes Intervention Study (SDIS) (2), both conducted in patients with type 1 diabetes, and the UK Prospective Diabetes Study
(UKPDS) (3) and Kumamoto Study (4), conducted in patients with type 2 diabetes, were particularly influential in this respect. As shown in Table 1, the results of these studies have been interpreted differently by the various professional bodies and there is a lack of consensus across the treatment guidelines $(5-10)$. Target $\mathrm{HbA}_{1 \mathrm{c}}$ levels vary widely from approximately $6.2 \%$ to as high as $7.5 \%$ but, based on data from the UKPDS, the general consensus is an $\mathrm{HbA}_{1 \mathrm{c}}$ level of $7 \%$ or lower.

\section{The importance of treating to goal}

There is an extensive evidence base supporting the benefits of treating to $\mathrm{HbA}_{1 \mathrm{c}}$ goal. Above all, decreasing $\mathrm{HbA}_{1 \mathrm{c}}$ levels reduces the risk of vascular complications (11) - the principal cause of diabetes-related morbidity and mortality. Importantly, therapeutic interventions that reduce the risk of complications, i.e. interventions that reduce glycaemia and blood pressure, do not significantly reduce quality of life unlike the longterm complications of diabetes (11). Diabetes-related healthcare costs increase substantially with the presence of long-term diabetes complications (12). However, intensive glycaemic control can reduce 
Table 1 Guidelines for target $\mathrm{HbA}_{1 \mathrm{c}} \%$.

\begin{tabular}{|c|c|c|c|}
\hline $\mathrm{ADA}^{5}$ & Non-diabetic $<6.0$ & Goal $<7.0$ & Additional action $>8.0$ \\
\hline IDF (type 1 diabetes) ${ }^{6}$ & Non-diabetic $<6.1$ & Adequate $6.2-7.5$ & Inadequate $>7.5$ \\
\hline IDF (type 2 diabetes) ${ }^{8}$ & Low risk $\leq 6.5$ & Arterial risk $>6.5$ & Microvascular risk $>7.5$ \\
\hline ACE/ACCE ${ }^{7}$ & Target $6.5-7.5$ & & \\
\hline $\mathrm{NICE}^{9}$ & Target $6.5-7.5$ & & \\
\hline $\mathrm{APDPG}^{10}$ & Optimal < 6.5 & Fair $6.5-7.5$ & Poor $>7.5$ \\
\hline
\end{tabular}

Superscript numbers refer to references.

IDF = International Diabetes Federation; ACE = American College of Endocrinology; NICE = National Institute of Clinical Excellence.

healthcare costs by reducing the cost of treating complications $(13,14)$.

The results of the DCCT showed a significant correlation between $\mathrm{HbA}_{1 \mathrm{c}}$ levels and the risk of microvascular complications (retinopathy, nephropathy, neuropathy and microalbinuria) in patients with type 1 diabetes (15). The lower the $\mathrm{HbA}_{1 \mathrm{c}}$ level, the greater the reduction in the relative risk of developing any of the long-term complications. The risk of complications increased over time and was greatest in patients with a long history of poor glycaemic control (15). A quarter of those patients who had $\mathrm{HbA}_{1 \mathrm{c}}>11 \%$ (also defined as worst glycaemic control) had evidence of diabetic retinopathy after just 5 years. In contrast, those with good glycaemic control $\left(\mathrm{HbA}_{1 \mathrm{c}}<7 \%\right)$ had a low risk of retinopathy for at least 10 years $(15,16)$.

Similarly, the results of the UKPDS showed that poor glycaemic control increases the risk of long-term complications in people with type 2 diabetes. The risk of both micro- and macrovascular complications (after adjustment for age, sex, ethnic group and duration of diabetes) was strongly associated with hyperglycaemia, and the incidence increased three fold over the range of $\mathrm{HbA}_{1 \mathrm{c}}<6 \%$ to $\mathrm{HbA}_{1 \mathrm{c}} \geq 10 \%$ (17). Extrapolation of data from the latter study showed that each $1 \%$ reduction in $\mathrm{HbA}_{1 \mathrm{c}}$ reduced the risk of microvascular complications by $37 \%(P<0.0001)$ and the risk of fatal and non-fatal myocardial infarction by $14 \%$ $(P<0.0001)$ (Fig. 1). There was no threshold level of $\mathrm{HbA}_{1 \mathrm{c}}$ above or below which the risk of complications ceased to increase or decrease respectively (17).

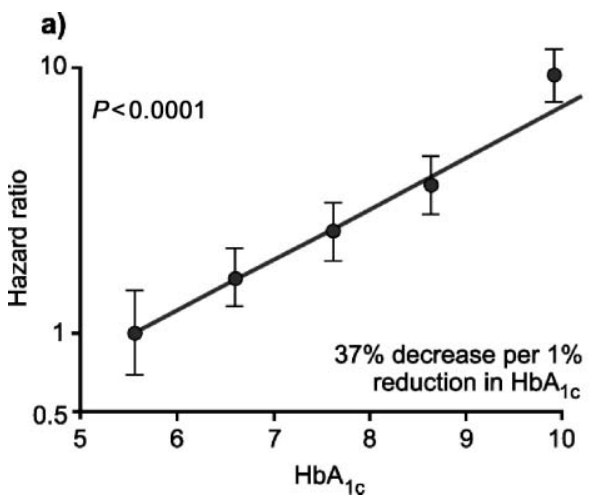

Figure 1 Association between $\mathrm{HbA}_{1 \mathrm{c}}$ and vascular complications: a) microvascular endpoints; b) fatal and non-fatal myocardial infarction (From (17), with permission from the BMJ Publishing Group).

\section{Most patients do not reach treatment goals}

Despite evidence that good glycaemic control has significant health and economic benefits, most patients with diabetes do not achieve recommended treatment goals. According to studies conducted in the USA, Europe and Asia Pacific, most patients have poor glycaemic control $\left(\mathrm{HbA}_{1 \mathrm{c}}>8 \%\right)$ and less than one-third, substantially less in some countries, achieve the recommended target levels for $\mathrm{HbA}_{1 \mathrm{c}}(18-20)$. For example, in the Diabcare-Asia Study (19), the mean $\mathrm{HbA}_{1 \mathrm{c}}$ level was $8.6 \%$, with only 21,13 or $7 \%$ of patients achieving recommended $\mathrm{HbA}_{1 \mathrm{c}}$ goals according to the criteria of the American Diabetes Association (ADA; <7\%), the European Diabetes Policy Group (EUDPG; $\leq 6.5 \%$ ) or the Asia Pacific Type 2 Diabetes Policy Group 1999 (APDPG; < 6.2\%) (Fig. 2; 19, note that the APDPG 2002 guidelines recommend a goal $\leq 6.5 \%$ ). These data are supported by numerous other studies. For instance, in the UK Asian Diabetes Study, a community-based study conducted in Birmingham and Coventry in the UK, $66 \%$ of patients had $\mathrm{HbA}_{1 \mathrm{c}}>7 \%$ (21). Why are so many patients failing to receive the benefits of good glycaemic control?

\section{Barriers to achieving glucose goals}

Barriers to optimal glycaemic control are present in almost every aspect of diabetes care. Although significant advances have been made in the past few decades,

\section{b)}

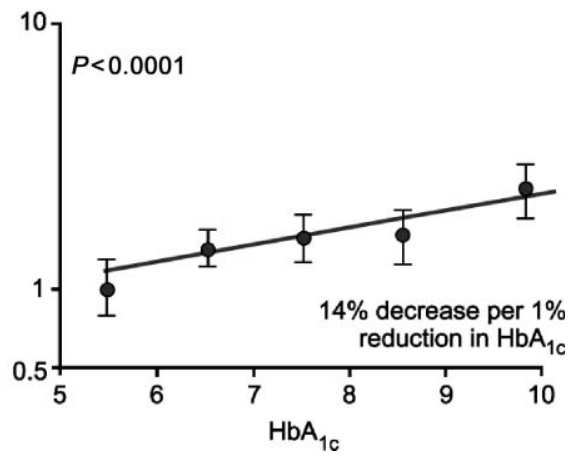




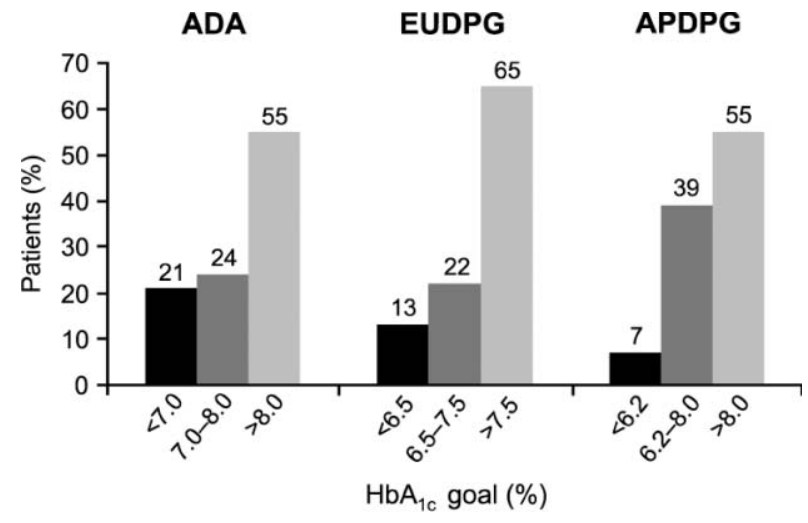

Figure 2 Proportion of patients with various degrees of glycaemic control as defined by different guidelines for treatment goals (From Chuang et al. (19), with permission from Blackwell Publishing). $A D A=$ American Diabetes Association; EUDPG = European Diabetes Policy Group; APDPG = Asian Pacific Type 2 Diabetes Policy Group.

there remain substantial limitations with current therapeutic options that may decrease patients' willingness to adhere to their medication. Furthermore, many patients and healthcare professionals underestimate the seriousness of diabetes and the importance of interventions to prevent long-term complications. There is a lack of training and education for health professionals, patients and their families. These problems are compounded by the progressive nature of the disease and the fact that most available treatment strategies fail to maintain glycaemic control in the long-term because of an ongoing decline in beta-cell function.

There are many treatment options for patients with type 2 diabetes, and there are major discrepancies among healthcare professionals about the optimal treatment strategies and about the appropriate timing of the strategies to be employed. In patients with newly diagnosed type 2 diabetes, lifestyle intervention (diet and exercise) is widely accepted as first-line therapy. If lifestyle changes fail to bring about improvements in glycaemic control, there are a number of options. In general, the first step is to supplement lifestyle changes with oral agent monotherapy, followed by oral combination therapy should monotherapy fail. However, if treatment targets are still not achieved physicians must choose between adding a third oral agent, combination therapy with oral agents plus insulin, or insulin therapy alone. This multitude of treatment options means that patients may fail on several different regimens, and therefore experience long periods of poor glycaemic control, before receiving insulin. Although the merits of early combination treatment with oral agents and/or insulin have been emphasised, this message does not seem to have filtered down to the average healthcare provider and, consequently, insulin therapy is inappropriately delayed in many patients who could otherwise benefit earlier from improved glycaemic control.

\section{Therapeutic barriers}

In addition to the reduced long-term efficacy with oral agents, current diabetes therapies lack flexibility for both patients and prescribers. For example, patients taking standard insulin formulations must adjust the timing and content of their meals to suit their insulin injection regimen.

Multiple daily insulin injections and/or a high pill load contribute to the daily burden of living with diabetes and can discourage adherence to therapy. Polypharmacy is a major reason for non-compliance with therapy (22); patients with type 2 diabetes may need to take as many as 16 tablets a day plus insulin injections to control glycaemia, blood pressure and cardiovascular (CVD) risk factors. Morris et al. (23), demonstrated that adequate adherence with treatment (defined as having prescriptions filled often enough to enable the person to take at least $90 \%$ of the recommended dosage of each medication) more than halved when patients were switched from monotherapy with a sulphonylurea or metformin to combination therapy with a sulphonylurea plus metformin.

Using current therapeutic options, there is a trade-off between the benefits of intensive glycaemic control and increased risk of hypoglycaemia - perhaps the greatest fear of insulin-treated type 1 and type 2 diabetes patients. In the DCCT for example, the lower risk of complications associated with intensive insulin therapy compared with conventional therapy was at the expense of increased risk of severe hypoglycaemia (1). Patients receiving intensive therapy were $2-3$ times more likely to experience a severe hypoglycaemic episode than those receiving conventional therapy (1). In the UKPDS, patients receiving intensive therapy with a sulphonylurea or insulin were also significantly more likely to experience a hypoglycaemic event than those receiving conventional therapy $(P<0.0001)$ (2). Thus, fear of hypoglycaemia is likely to be an important barrier to achieving blood glucose targets. Numerous other therapy-related barriers such as cost, availability of diagnostic tools, supply issues and fear of injections may prevent patients from achieving good glycaemic control (see 24 for review).

\section{Patient-related barriers}

A variety of issues relating to lifestyle, education, psychology and the environment can impair diabetes self-management. Behavioural and medical barriers, such as obesity, physical inactivity, substance abuse, smoking and non-compliance with therapy, are often closely interrelated. It is therefore important for physicians to understand the barriers to glycaemic control from the patient's perspective and to combine psychosocial support with appropriate pharmacological therapy (25). Emotional well-being is critical for effective self-care (26) and depression, which is common among people with diabetes, is likely to have a major 
effect on patients' attitudes to therapy and, ultimately, treatment outcomes. Patient-related barriers to achieving glucose goals are discussed in further detail in the following articles (27-30).

\section{Healthcare system-related barriers}

Poor access and/or use of specialist care can also affect treatment outcomes. In a study in patients with type 1 diabetes, the longer the proportion of diabetes duration spent in specialist care, the lower the risk of overt nephropathy (risk ratio 0.43, 95\% CI 0.21-0.88), neuropathy (risk ratio $0.54,95 \%$ CI $0.35-0.83$ ) and coronary artery disease (risk ratio 0.65, 95\% CI $0.37-1.1)$. This trend was independent of diabetes duration, demographic characteristics, healthcare practices and physiological risk factors (31). Thus, specialist rather than general diabetes care may result in better glycaemic control and a lower incidence of some diabetes complications.

\section{Regional and cultural differences in glycaemic control}

Intercultural differences exist in the proportion of patients achieving good glycaemic control (32). For example, data from the National Health and Nutrition Examination Study (NHANES) III showed that a higher proportion of African American $(P<0.01)$ and Hispanic (NS) patients with type 2 diabetes have $\mathrm{HbA}_{1 \mathrm{c}} \geq 7 \%$ compared with Caucasian patients (58.2, 65.5 and 55.1\%, respectively) (32). Data from patients with type 1 diabetes in the South Auckland Diabetes Project also showed regional differences in $\mathrm{HbA}_{1 \mathrm{c}}$, with people of European descent generally having better glycaemic control (mean $\mathrm{HbA}_{1 \mathrm{c}}$ $7.4 \pm 1.7 \%$ ) than the indigenous Maori population

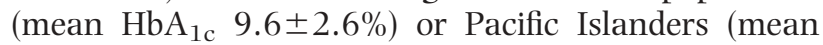
$\mathrm{HbA}_{1 \mathrm{c}} 9.2 \pm 2.6 \%$ ) (33). However, irrespective of race or ethnicity, the data consistently show that the majority of patients with diabetes do not reach the recommended treatment goals, as shown across 12 countries in the Diabcare-Asia study (19).

\section{Conclusions}

The rising incidence of type 2 diabetes and associated burden of diabetes-related complications mean that the management of diabetes must be improved. There are multiple barriers to optimal glycaemic control that need to be overcome so that the established benefits of good glycaemic control can be experienced by more people with diabetes. The following papers in this supplement $(27-30)$ show that breaking down these barriers requires that treatment goals and strategies are individualised, bearing in mind patients' needs and goals as well as socioeconomic, psychological and pathophysiological factors. In addition, new treatment options that offer superior flexibility, convenience and acceptability will help to implement more effective diabetes management strategies and to improve diabetes outcomes.

\section{References}

1 Diabetes Control and Complications Trial Research Group. The effect of intensive treatment of diabetes on the development and progression of long-term complications in insulin-dependent diabetes mellitus. New England Journal of Medicine 1993329 977-986.

2 Reichard P, Nilsson BY \& Rosenqvist V. The effect of long-term intensified insulin treatment on the development of microvascular complications of diabetes mellitus. New England Journal of Medicine $1993329304-309$.

3 UK Prospective Diabetes Study Group. Intensive blood glucose control with sulphonylureas or insulin compared with conventional treatment and risk of complications in patients with type 2 diabetes (UKPDS 33). Lancet $1998352837-853$.

4 Ohkubo Y, Kishikawa H, Araki E, Miyata T, Isami S, Motoyoshi S, Kojima Y, Furuyoshi N \& Shichiri M. Intensive insulin therapy prevents the progression of diabetic microvascular complications in Japanese patients with non-insulin-dependent diabetes mellitus: a randomized prospective 6-year study. Diabetes Research and Clinical Practice 199528 103-117.

5 American Diabetes Association. Clinical Practice Recommendations 2000. Diabetes Care 200023 (Suppl 1) S1-S116.

6 European Diabetes Policy Group. A desktop guide to Type 1 (insulin-dependent) diabetes mellitus. Diabetic Medicine 199916 253-266.

7 American College of Endocrinology. Consensus Status on Guidelines for Glycemic Control. Endocrine Practice 20028 (Suppl 1) 5-11.

8 European Diabetes Policy Group. A desktop guide to Type 2 diabetes mellitus. Diabetic Medicine $199916716-730$.

9 McIntosh A, Hutchinson A, Home PD, Brown F, Bruce A, Damerell A, Davis R, Field R, Frost G, Marshall S, Roddick J, Tesfaye S, Withers H, Suckling R, Smith S, Griffin S, Kaltenthaler E, Peters J \& Feder G. Clinical guidelines and evidence review for Type 2 diabetes: management of blood glucose. Sheffield: ScHARR, University of Sheffield, 2001.

10 Asian-Pacific Type 2 Diabetes Policy Group. Type 2 diabetes. Practical Targets and Treatments, edn 3. Sydney: Health Communications Australia Pty Ltd and In vivo, 2002.

11 UKPDS Group. Quality of life in type 2 diabetic patients is affected by complications but not by intensive policies to improve blood glucose or blood pressure control (UKPDS 37). Diabetes Care 199922 1125-1136.

12 Clarke P, Gray A, Legood R, Briggs A \& Holman R. The impact of diabetes-related complications on healthcare costs: results from the United Kingdom Prospective Diabetes Study (UKPDS Study No. 65). Diabetic Medicine $200320442-450$.

13 Gray A, Raikou M, McGuire A, Fenn P, Stevens R, Cull C, Stratton I, Adler A, Holman R \& Turner R. Cost effectiveness of an intensive blood glucose control policy in patients with type 2 diabetes: economic analysis alongside randomised controlled trial (UKPDS 41). United Kingdom Prospective Diabetes Study Group. British Medical Journal 2000320 1373-1378.

14 Herman WH \& Eastman RC. The effects of treatment on the direct costs of diabetes. Diabetes Care 199821 (Suppl 3) C19-C24.

15 Skyler JS. Diabetic complications. The importance of glucose control. Endocrinology and Metabolism Clinics of North America 1996 25 243-254.

16 DCCT Research Group. The relationship of glycemic exposure $\left(\mathrm{HbA}_{1 \mathrm{c}}\right)$ to the risk of development and progression of retinopathy in the diabetes control and complications trial. Diabetes 1995 44 968-983. 
17 Stratton IM, Adler AI, Neil HA, Matthews DR, Manley SE, Cull CA, Hadden D, Turner RC \& Holman RR. Association of glycaemia with macrovascular and microvascular complications of type 2 diabetes (UKPDS 35): prospective observational study. British Medical Journal $2000321405-412$.

18 Harris MI, Eastman RC, Cowie CC, Flegal KM \& Eberhardt MS. Racial and ethnic differences in glycemic control of adults with type 2 diabetes. Diabetes Care 199922 403-408.

19 Chuang LM, Tsai ST, Huang BY \& Tai TY. Diabcare-Asia 1998 Study Group. The status of diabetes control in Asia - a cross-sectional survey of 24317 patients with diabetes mellitus in 1998 . Diabetic Medicine 200219 978-985.

20 Liebl A, Mata M \& Eschwege E. CODE-2 Advisory Board. Evaluation of risk factors for development of complications in Type II diabetes in Europe. Diabetologia 200245 S23-S28.

21 O'Hare JP, Raymond NT, Mughal S, Dodd L, Hanif W, Ahmed Y, Mishra K, Jones A, Kumar S, Szczepura A, Hillhouse EW \& Barnett AH, on behalf of the UKADS study group. Evaluation of delivery of enhanced diabetes care for patients of South Asian ethnicity: the United Kingdom Asian Diabetes Study (UKADS). Diabetic Medicine (In Press).

22 Donnan PT, MacDonald TM \& Morris AD. Adherence to prescribed oral hypoglycaemic medication in a population of patients with Type 2 diabetes: a retrospective cohort study. Diabetic Medicine $200219279-284$.

23 Morris AD, Brennan GM, MacDonald TM \& Donnan PT. Population-based adherence to prescribed medication in type 2 diabetes: a cause for concern. Diabetes 200049 (Suppl 1) 307.

24 Home PD, Boulton AJM, Jimenez J, Landgraf R, Osterbrink B \& Christiansen JS. Issues relating to the early or earlier use of insulin in type 2 diabetes. Practical Diabetes International 2003 20 63-71.

25 Snoek FJ. Barriers to good glycaemic control: the patient's perspective. International Journal of Obesity and Related Metabolic Disorders 200024 (Suppl 3) S12-S20.

26 Diabetes Attitudes, Wishes and Needs (DAWN) Study group. DAWN Study Report, 2001.

27 Gagliardino JJ. Resourcing issues. European Journal of Endocrinology 2004151 (Suppl) S15-S17.

28 Skinner TC. Psychological barriers. European Journal of Endocrinology 2004151 (Suppl) S9-S13.

29 Funnell MM. Overcoming obstacles: collaboration for change. European Journal of Endocrinology 2004151 (Suppl) S19-S22.

30 Heinemann L. Overcoming obstacles: new management options. European Journal of Endocrinology 2004151 (Suppl) S3-S7.

31 Zgibor JC, Songer TJ, Kelsey SF, Drash AL \& Orchard TJ. Influence of health care providers on the development of diabetes complications: long-term follow-up from the Pittsburgh Epidemiology of Diabetes Complications Study. Diabetes Care $2002 \mathbf{2 5}$ 1584-1590.

32 Harris MI. Racial and ethnic differences in health care access and health outcomes for adults with type 2 diabetes. Diabetes Care 200124 454-459.

33 Zgibor JC \& Simmons D. Barriers to blood glucose monitoring in a multiethnic community. Diabetes Care $2002251772-1777$.

Received 19 May 2004

Accepted 24 May 2004 